\title{
The impact of childhood abuse and recent stress on serum brain-derived neurotrophic factor and the moderating role of BDNF $\mathrm{Val}^{66} \mathrm{Met}$
}

\author{
Bernet M. Elzinga • Marc L. Molendijk • Richard C. Oude Voshaar • \\ Boudewijn A. A. Bus • Jos Prickaerts • Philip Spinhoven • Brenda J. W. H. Penninx
}

Received: 14 March 2010 /Accepted: 12 July 2010 /Published online: 12 August 2010

(C) The Author(s) 2010. This article is published with open access at Springerlink.com

\begin{abstract}
Rationale Recent findings show lowered brain-derived neurotrophic factor (BDNF) levels in major depressive disorder (MDD). Exposure to stressful life events may (partly) underlie these BDNF reductions, but little is known about the effects of early or recent life stress on BDNF levels. Moreover, the effects of stressful events on BDNF levels may in part be conditional upon a common variant on the BDNF gene (Val ${ }^{66} \mathrm{Met}$; RS6265), with the Met allele being associated with a decrease in activitydependent secretion of BDNF compared to the Val allele.
\end{abstract}

\footnotetext{
Funding The NESDA study infrastructure is financed by the Geestkracht program of ZonMW; the Dutch Scientific Organization, Medical Sciences (grant no. 10.000.1002); and by complementary funding from participating mental health care institutions (GGZ Buitenamstel, GGZ Drenthe, GGZ Friesland, GGZ Geestgronden, GGZ Rivierduinen, and Lentis) and Universities (Leiden University Medical Center, University Medical Center Groningen, and VU University Medical Center). BDNF measurements were financed with NWO (Dutch Scientific Organization) VIDI-grant (grant no. 016.085.353) awarded to Dr. B.M. Elzinga. There is no conflict of interest.
}

\footnotetext{
B. M. Elzinga $(\varangle) \cdot$ M. L. Molendijk $\cdot$ P. Spinhoven Department of Clinical Health and Neuropsychology, Leiden Institute for Brain and Cognition (LIBC),

Leiden University,

Leiden, the Netherlands

e-mail: elzinga@fsw.leidenuniv.nl
}

R. C. Oude Voshaar

Department of Psychiatry, University Medical Center Groningen, Groningen, the Netherlands

R. C. Oude Voshaar • B. A. A. Bus

Nijmegen Centre for Evidence-Based Practice (NCEBP),

Department of Psychiatry,

Radboud University Nijmegen Medical Centre,

Nijmegen, the Netherlands
Methods We investigated cross-sectionally in 1,435 individuals with lifetime MDD the impact of childhood abuse (CA) and recent life events on serum BDNF levels and assessed whether the impact of these events was moderated by the BDNF Val ${ }^{66}$ Met polymorphism.

Results Overall, BDNF Met carriers had reduced serum BDNF levels when exposed to CA in a dose-dependent way. Moreover, exposure to recent life events was also associated with decreases in BDNF levels, but this was independent of BDNF $\mathrm{Val}^{66}$ Met. Moreover, when not

\section{J. Prickaerts}

Department of Psychiatry and Neuropsychology,

Maastricht University,

Maastricht, the Netherlands

P. Spinhoven • B. J. W. H. Penninx

Department of Psychiatry, Leiden University Medical Center, Leiden, the Netherlands

\section{B. J. W. H. Penninx}

Department of Psychiatry,

EMGO Institute and Neuroscience Campus,

VU University Medical Center,

Amsterdam, the Netherlands 
exposed to CA, Met carriers had higher BDNF levels than the Val/Val individuals, who did not show decreases in BDNF associated with CA. Finally, these findings were only apparent in the MDD group without comorbid anxiety. Conclusions These gene-environment interactions on serum BDNF levels suggest that Met carriers are particularly sensitive to (early) stressful life events, which extends previous findings on the moderating role of the $\mathrm{BDNF} \mathrm{Val}^{66} \mathrm{Met}$ polymorphism in the face of stressful life events.

Keywords Stress · BDNF. Depression - Gene .

Childhood abuse

\section{Introduction}

Major depressive disorder (MDD) is one of the most common psychiatric disorders, which involves dysregulation of affect, motivation, appetite, sleep, and cognitive dysfunctions, resulting in impairments in several aspects of life. An accumulating body of research indicates that MDD is often the result of the interplay between genetic vulnerability and environmental factors (Kendler 2005). In particular, child abuse (CA) is a significant etiological factor in the development and persistence of MDD across the life cycle (Charney 2004; Heim and Nemeroff 2001; McLaughlin et al. 2010; Spinhoven et al. 2010). Moreover, exposure to stress during adulthood (for example, divorce and job loss) often precipitates or exacerbates depressive symptoms (Kendler et al. 1999). In some instances, stressful events in adulthood interact with stressful events that occurred early in life to contribute to the process of stress sensitization (Post 2007).

Given its major contribution to the burden of disease, it is important to identify underlying biological mechanisms that might lead from stress exposure to MDD. One of the neurobiological changes that may be triggered by both chronic and acute stress is a downregulation of brainderived neurotrophic factor (BDNF). The neurotrophin BDNF is a critical regulator of the formation, plasticity, and integrity of neurons in brain circuits that regulate emotion (Angelucci et al. 2005; Duman and Monteggia 2006). In animals, exposure to stress early in life (for example, repeated maternal separation) has been found to induce a relative decrease in the expression of BDNF and to subsequent neuronal atrophy and degeneration in the hippocampus and the cortex, which can persist into adulthood (Murakami et al. 2005; Roceri et al. 2004; Song et al. 2006; Smith et al. 1995). According to the "neurotrophic hypothesis of depression," these reductions in BDNF expression may account for the pathophysiology of MDD (Duman and Monteggia 2006). Consistent with this idea, several studies found decreased central (Karege et al. 2005) and peripheral levels of BDNF (Molendijk et al. 2010; Sen et al. 2008) in patients with MDD. More specifically, in line with the animal models, one study found lowered plasma BDNF in depressed women with a history of childhood physical neglect compared to nonabused depressed women and controls (Grassi-Oliveira et al. 2008). A study among bipolar patients reported similar reductions in serum BDNF levels in patients exposed to stressful life events (Kauer-Sant'Anna et al. 2007).

A common single-nucleotide polymorphism (SNP) on the BDNF gene is $\mathrm{Val}^{66}{ }^{6 e t}$. Val ${ }^{66}$ Met refers to a valine (Val) to methionine (Met) insertion at codon 66 (Egan et al. 2003). This SNP affects intracellular processing and secretion of BDNF, with the Met allele being associated with a decrease in activity-dependent secretion of BDNF compared to the Val allele (Egan et al. 2003). Most studies have compared carriers of a Met allele (Val/Met) with individuals who are homozygous for the Val allele (Val/ Val) because individuals who are homozygous for the Met allele (Met/Met) are rare in Caucasians (approximately $4 \%$ ). In general, these studies have shown that Met carriers have lower hippocampal gray matter (Bueller et al. 2006; Pezawas et al. 2004) and poorer episodic memory performance (Egan et al. 2003) compared to individuals homozygous for the Val allele. Moreover, several studies have reported that Met carriers are more vulnerable to the effects of CA compared to individuals who are homozygous for the Val allele in terms of depressive symptoms (Kaufman et al. 2006; Wichers et al. 2008) and hippocampal gray matter (Gatt et al. 2009).

Whereas variations on the BDNF gene seem to play an important role in MDD, little is known on how variations on the BDNF polymorphism $\mathrm{Val}^{66} \mathrm{Met}$ may influence serum BDNF levels of individuals who have been exposed to $\mathrm{CA}$ and/or recent negative life events. A closer examination of the impact of $\mathrm{CA}$ and recent life stress and the moderating role of variations on the BDNF polymorphism $\mathrm{Val}^{6}{ }^{6} \mathrm{Met}$ on blood-derived BDNF levels may help to elucidate the neurobiological changes that underlie the susceptibility of developing MDD after exposure to stressful life events. Therefore, using data from the Netherlands Study of Depression and Anxiety (NESDA, see Penninx et al. 2008), we investigated, crosssectionally, the impact of $\mathrm{CA}$ and recent life events on serum BDNF levels in a large sample of individuals with lifetime MDD $(n=1,435)$ and assessed whether the impact of these stressful life events was moderated by variations on the BDNF $\mathrm{Val}^{66}$ Met polymorphism (comparing Met carriers to homozygous Val carriers). Based on findings in 
animals and humans, we hypothesized that both CA and recent life events would reduce serum BDNF levels, particularly in Met carriers of the Val ${ }^{66}$ Met polymorphism.

\section{Materials and methods}

\section{Participants}

Participants were derived from NESDA (for details on the design, objectives, and protocol of NESDA, see Penninx et al. 2008). In brief, NESDA is a prospective cohort study $(N=2,981)$ that recruited subjects with a current MDD and/or an anxiety disorder, patients with MDD and/or an anxiety disorder in remission, and healthy controls without a history or current MDD or anxiety disorder in specialized mental health care, primary care, and the general population. A general inclusion criterion was an age of 18 through 65 years. Excluded were individuals with a primary diagnosis of psychotic, obsessive compulsive, bipolar, or severe addiction disorder (requiring care in specialized addiction clinics). A second exclusion criterion was not being fluent in Dutch. At baseline, participants provided blood and underwent a medical examination. The study protocol was approved by the Ethical Review Board of the VU University Medical Center and by local review boards of each participating institute. After full information about the study was provided, written informed consent was obtained from all participants.

From the NESDA baseline sample, we selected 1,435 participants $(48.1 \%)$, with a mean age of 42.2 years $( \pm 12.4)$ and $30.7 \%(n=440)$ males. To investigate individuals with a vulnerability to MDD, our selection was based on the following criteria: (1) participants had to have a current or lifetime diagnosis of MDD; (2) genomic data, data on serum BDNF levels, and measurements of CA and recent stress had to be available; and (3) participants had to be of North-European descent.

DSM-IV diagnoses (APA 1994) of MDD and anxiety disorders (generalized anxiety, social phobia, panic with or without agoraphobia, or agoraphobia without history of panic) were determined by means of the Composite Interview Diagnostic Instrument (CIDI; Wittchen et al. 1991) that was administered by trained research staff. The CIDI has high reliability (Wacker et al. 2006) and validity (Wittchen et al. 1991). Depression symptom severity was assessed using the Inventory of Depressive Symptoms Self-Report version (Rush et al. 1996). The use of antidepressants was gauged on by selfreport and drug container observation.

CA was assessed retrospectively using a semistructured childhood trauma interview, previously used in the Netherlands Mental Health Survey and Incidence Study (de Graaf et al. 2004a, b). In this interview, participants were asked whether they had experienced before the age of 16 years one of the following types of trauma: emotional neglect, psychological, and physical and/or sexual abuse. Emotional neglect was described as "Nobody ever listened to you at home, your problems were ignored, you had the feeling not being able to find any attention or support from your parents." Psychological abuse was described as "You were verbally abused, unjustly punished, your brothers and sisters were favored, but no bodily harm was done." Physical abuse was defined as "Being kicked, hit with or without an object, or being physically maltreated in any other way." Sexual abuse was defined as "Being touched sexually by anyone against your will, or being forced to touch anyone sexually." After an affirmative answer, details on the frequency of these events and the perpetrators involved were asked for. Because of the large overlap between emotional neglect and emotional abuse, the two types of abuse were merged together as "emotional abuse." Answers were coded as zero, one, two, or three reported types of CA. The mean number ( \pm standard deviation (SD)) of CA types was 1.12 $( \pm 1.15)$, with $42.7 \%(n=613)$ reporting no $\mathrm{CA}, 21.6 \%$ $(n=310)$ reporting one type of CA, $17.1 \% \quad(n=246)$ reporting two types of $\mathrm{CA}$, and $18.5 \%(n=266)$ reporting three types of CA. For the main analysis of variance (ANOVA), the presence of CA was defined as 0 versus $\geq 1$ type of CA. For dose-response analyses, individuals were divided into three categories: individuals reporting no CA, one type of CA, and two or more types of CA.

The occurrence of 12 recent stressful life events ("recent stress") was assessed using the List of Threatening Events Questionnaire (LTE-Q; Brugha et al. 1985; Brugha and Cragg 1990). These events reflect the presence of life stressors during the past year, such as serious illness and injury, death of close friend or relative, unemployment, major financial loss, and loss of important relationships. The LTE-Q has good test-retest reliability, high agreement between participant and informant ratings, and good agreement with interview-based ratings (Brugha and Cragg 1990). Answers were coded as the total number of life events. The mean number $( \pm \mathrm{SD})$ of reported stressful life events was $0.68( \pm 1.0)$, with $58.4 \%$ $(n=838)$ reporting no life events, $23.6 \%(n=338)$ reporting one event, $12.1 \%(n=173)$ reporting two events, $4.5 \%$ $(n=64)$ reporting three events, $0.6 \%(n=9)$ reporting four events, $0.6 \%(n=9)$ reporting five events, $0.2 \%(n=3)$ reporting six events, and $0.1 \%(n=1)$ reporting seven events. For the main analyses, "recent stress" was defined as 0 versus $\geq 1$ incidents of stressful life events during the preceding year, whereas for the dose-response analyses, individuals were divided into three groups: individuals reporting no life event, one life event, and two or more life events in the past year. 


\section{Genotyping}

Genotyping of the subjects was performed by Perlegen Sciences using high oligonucleotide arrays (Mountain View, CA, USA). For detailed descriptions on the procedures according to which genotyping was performed, we refer to Boomsma et al. (2008). The $\mathrm{Val}^{66}$ Met polymorphism (Dibisnp 6265) was extracted from whole genome data using PLINK software (http://pngu.mgh.harvard.edu/ pur cell/plink). Val ${ }^{66}$ Met was in the equilibrium as stated by Hardy and Weinberg $(P=.28)$. Moreover, genotype frequencies (Val ${ }^{66}$ Val $65.5 \%$, $\mathrm{Val}^{66}$ Met $32.5 \%$, and $\mathrm{Met}^{66}$ Met $2 \%$ ) were similar to those reported in previous studies on Caucasian populations (Gatt et al. 2009; Lang et al. 2009). Individuals who were homozygous for the Met allele were merged with the heterozygous individuals into a group of Met carriers $(n=495)$ and compared to homozygous Val carriers $(n=940)$.

\section{Serum BDNF measurements}

Fifty milliliters of blood was withdrawn into vacuum tubes between 07:30 a.m. and 09:30 a.m. after an overnight fast. Following blood collection, serum was separated and stored at $-85^{\circ} \mathrm{C}$ until it was assayed. BDNF protein levels were measured using the Emax ImmunoAssay system from Promega according to the manufacturer's protocol (Madison, WI, USA). Greiner Bio-One high-affinity 96-well plates were used. Serum samples were diluted 100 times, and the absorbency was read in duplicate using a Bio-Rad Benchmark microplate reader at $450 \mathrm{~nm}$. Serum BDNF protein levels were expressed in nanograms per milliliter. The intra-assay and inter-assay coefficients of variation were within 3\% and $9 \%$, respectively. Prior to analyses, BDNF values that were three $\mathrm{SD}$ above the mean $(n=5,0.35 \%)$ were trimmed to a value of the mean plus three SDs. One BDNF value $(0.07 \%)$ was below the reliable detection limit of the ELISA kit of $1.56 \mathrm{ng} / \mathrm{ml}$ and was set at the lower detection limit of $1.56 \mathrm{ng} / \mathrm{ml}$.

\section{Statistical analysis}

ANOVAs and $\chi^{2}$ tests were used to determine betweengroup differences in demographical and clinical features (see Table 1).

Estimates of the main and interaction effects of CA, recent stress, and $\mathrm{Val}^{66} \mathrm{Met}$ on serum levels of BDNF were performed using $2(\mathrm{CA}$ : yes $/$ no $) \times 2$ (recent stress: yes/no $) \times 2\left(\right.$ BDNF Val ${ }^{66}$ Met: Val/Val vs. Met carriers $)$ ANOVA. CA and recent stress were entered as dichotomous (yes/no) variables in order to have a maximal number of subjects in each cell. Since gender, age, years of education, symptom severity of depression, presence of current MDD vs remitted MDD, presence of a current comorbid anxiety disorder, use of an antidepressant, exact time of morning blood withdrawal, and the duration of serum storage have been discussed as potential sources of between-subject variation in BDNF levels (Begliuomini et al. 2008; Sen et al. 2008; Trajkovska et al. 2007), we statistically controlled for their possible confounding effects by adding these variables as covariates to the analysis. Significant interactions were followed up by independent $t$ tests.

Secondly, because recent studies suggest that the symptomatology and causal pathways for MDD without comorbid anxiety disorder may be quite distinct to those for MDD with comorbid anxiety disorder(s) (see Gatt et al. 2009), we repeated the same $2(\mathrm{CA}$ : yes $/$ no $) \times 2$ (recent stress: yes/no $) \times 2\left(\mathrm{BDNF} \mathrm{Val}^{66} \mathrm{Met}: \mathrm{Val} / \mathrm{Val}\right.$ vs. Met carriers) ANOVA in participants with (lifetime) MDD without comorbid anxiety (MDD-, $n=401$ ) and individuals with (lifetime) MDD and comorbid anxiety disorders (MDD+ANX, $n=1,033)$, separately.

Finally, to asses dose-response relations between CA and recent stress and BDNF levels, additional ANOVAs were conducted in the case of significant main effects of $\mathrm{CA}$ and/or recent stress or interactions with BDNF $\mathrm{Val}^{66} \mathrm{Met}$, based on three categories (no CA or recent life events vs one type of CA or recent life event vs two or more types of CA or recent life events).

Computations were performed in PASW version 18.0 (PASW, Chicago, IL, USA). Statistical significance was set at $P<.05$ (two-sided). Effect sizes were presented as Cohen's $d$ (1988).

\section{Results}

Demographics

Table 1 shows the demographical and clinical characteristics by $\mathrm{Val}^{66} \mathrm{Met}$, reported history of $\mathrm{CA}$, and recent stressful life events. Exposure to $\mathrm{CA}$ and recent stressful life events was independent of BDNF genotype $(P=.13$ and $P=.74$, respectively). Exposure to recent stressful life events tended to be reported somewhat more often in individuals with a history of CA $(P=.07)$. Individuals who were homozygous for the Val allele had more years of education compared to individuals who carried a Met allele. Individuals who reported CA were of older age and more likely to be female, to have a current episode of MDD, to have more chronic MDD, to have greater symptom severity of MDD, and to have a comorbid anxiety and alcohol use disorder compared to individuals who did not report CA. Individuals reporting recent life events were of younger 
Table 1 Demographic and clinical characteristics by brain-derived neurotrophic factor genotype (Val ${ }^{66}$ Met) and exposure to child abuse and recent stressful events $(N=1,435)$

\begin{tabular}{|c|c|c|c|c|c|c|c|c|c|}
\hline & \multicolumn{4}{|c|}{$\mathrm{Val}^{66} \mathrm{Val}(n=940)$} & \multicolumn{4}{|c|}{$\mathrm{Val}^{66} \operatorname{Met}(n=495)$} & \multirow[t]{3}{*}{$P$ value } \\
\hline & \multicolumn{2}{|c|}{ No abuse $(n=388)$} & \multicolumn{2}{|c|}{ Abuse $(n=552)$} & \multicolumn{2}{|c|}{ No abuse $(n=225)$} & \multicolumn{2}{|c|}{ Abuse $(n=270)$} & \\
\hline & $\begin{array}{l}\text { No recent } \\
\text { stress } \\
(n=237)\end{array}$ & $\begin{array}{l}\text { Recent } \\
\text { stress } \\
(n=151)\end{array}$ & $\begin{array}{l}\text { No recent } \\
\text { stress } \\
(n=309)\end{array}$ & $\begin{array}{l}\text { Recent } \\
\text { stress } \\
(n=243)\end{array}$ & $\begin{array}{l}\text { No recent } \\
\text { stress } \\
(n=138)\end{array}$ & $\begin{array}{l}\text { Recent } \\
\text { stress } \\
(n=87)\end{array}$ & $\begin{array}{l}\text { No recent } \\
\text { stress } \\
(n=154)\end{array}$ & $\begin{array}{l}\text { Recent } \\
\text { stress } \\
(n=116)\end{array}$ & \\
\hline Male, \% & 38.0 & 32.5 & 25.9 & 26.3 & 31.2 & 37.9 & 31.8 & 27.6 & $<.05^{\mathrm{a}}$ \\
\hline Age (years) & $42.3 \pm 12.8$ & $38.5 \pm 13.7$ & $44.1 \pm 11.4$ & $42.2 \pm 11.8$ & $41.8 \pm 13.3$ & $39.5 \pm 12.7$ & $44.4 \pm 11.7$ & $41.7 \pm 12.5$ & $<.01^{\mathrm{a}, \mathrm{b}}$ \\
\hline Education (years) & $12.3 \pm 3.1$ & $12.1 \pm 3.2$ & $12.2 \pm 3.4$ & $11.8 \pm 3.3$ & $12.1 \pm 3.0$ & $11.2 \pm 3.1$ & $12.0 \pm 3.1$ & $11.4 \pm 3.3$ & .06 \\
\hline Body mass index & $26.2 \pm 4.9$ & $25.1 \pm 4.4$ & $25.7 \pm 5.3$ & $26.0 \pm 5.3$ & $25.3 \pm 4.9$ & $25.4 \pm 4.8$ & $26.5 \pm 5.4$ & $25.7 \pm 5.6$ & .23 \\
\hline Smoker, \% & 31.3 & 42.9 & 38.0 & 41.8 & 34.1 & 48.8 & 3.3 & 48.2 & $<.01^{\mathrm{b}}$ \\
\hline Alcohol dependent, \% & 13.9 & 13.6 & 22.0 & 23.9 & 18.8 & 14.9 & 20.8 & 29.3 & $<.01^{\mathrm{a}}$ \\
\hline Emotional abuse, \% & NA & NA & 93.8 & 94.8 & NA & NA & 94.4 & 96.3 & .79 \\
\hline Physical abuse, \% & NA & NA & 27.8 & 34.9 & NA & NA & 27.1 & 40.4 & $<.05^{\mathrm{b}}$ \\
\hline Sexual abuse, $\%$ & NA & NA & 38.2 & 29.3 & NA & NA & 29.2 & 38.5 & .09 \\
\hline$>1$ event of abuse, $\%$ & NA & NA & 63.1 & 64.2 & NA & NA & 53.9 & 67.2 & .10 \\
\hline$>1$ event of recent stress, $\%$ & NA & 47.7 & NA & 43.2 & NA & 58.6 & NA & 32.8 & $<.05^{\mathrm{a}}$ \\
\hline $\begin{array}{l}\text { Current MDD } \\
\text { (6 months), \% }\end{array}$ & 46.4 & 54.3 & 57.9 & 68.3 & 59.4 & 54.0 & 54.5 & 69.8 & $<.001^{\mathrm{a}, \mathrm{b}}$ \\
\hline Chronic $\mathrm{MDD}^{\mathrm{c}}$ & 24.3 & 22.7 & 28.1 & 33.2 & 21.5 & 28.2 & 24.6 & 37.4 & $<.05^{\mathrm{a}, \mathrm{b}}$ \\
\hline MDD severity (IDS) & $22.1 \pm 12.8$ & $24.3 \pm 12.4$ & $27.7 \pm 13.2$ & $31.2 \pm 12.4$ & $24.0 \pm 13.5$ & $23.2 \pm 13.5$ & $26.7 \pm 13.1$ & $29.7 \pm 11.6$ & $<.001^{\mathrm{a}, \mathrm{b}}$ \\
\hline Comorbid anxiety $^{\mathrm{d}}, \%$ & 30.0 & 28.5 & 41.4 & 49.8 & 33.3 & 33.2 & 35.1 & 46.6 & $<.01^{\mathrm{a}, \mathrm{b}}$ \\
\hline Antidepressant use $\mathrm{e}^{\mathrm{e}}, \%$ & 35.0 & 33.1 & 39.3 & 42.8 & 30.4 & 26.4 & 39.6 & 44.0 & $<.05^{\mathrm{a}}$ \\
\hline
\end{tabular}

IDS inventory of depressive symptoms, $M D D$ major depressive disorder

${ }^{\text {a }}$ There is a difference at $P<.05$ between the no abuse group and the abuse group

${ }^{\mathrm{c}}$ There is a difference at $P<.05$ between the no recent stress group and the recent stress group

${ }^{\mathrm{c}}$ Symptoms were considered chronic if they were present for at least 24 months during the last 5 years

${ }^{\mathrm{d}}$ Included a diagnosis of social phobia, panic disorder with and without agoraphobia, agoraphobia, or generalized anxiety disorder during the last six month

${ }^{\mathrm{e}}$ Included the use of noradrenergic and specific serotonergic antidepressants, serotonin and norepinephrine reuptake inhibitors, selective serotonin reuptake inhibitors, St. John's wort, and tricyclic antidepressants

age, had less years of education, and were more likely to smoke, to have a current episode of MDD, to have chronic MDD, to have greater symptom severity, and to have a comorbid anxiety disorder (see Table 1). No other main effects nor $\mathrm{Val}^{66} \mathrm{Met} \times \mathrm{CA}$, $\mathrm{Val}^{66} \mathrm{Met} \times$ recent stress, or $\mathrm{Val}^{66} \mathrm{Met} \times \mathrm{CA} \times$ recent stress interactions were found.

Impact of childhood abuse, recent stress, and Val ${ }^{66} \mathrm{Met}$ on serum BDNF levels

Using a $2(\mathrm{CA}$ : yes $/$ no $) \times 2$ (recent stress: yes $/$ no $) \times 2($ BDNF Val ${ }^{66}$ Met: Val/Val vs. Met carriers) ANOVA on serum BDNF levels, we found no main effect of CA $(P=.38)$ nor a main effect of $\mathrm{Val}^{66} \mathrm{Met}$ on BDNF levels $(P=.33)$, but BDNF Val ${ }^{66}$ Met moderated the effects of CA on serum BDNF levels $\left(F_{1,1,416}=5.57, P=.018\right.$, see Fig. 1$)$. Met carriers reporting $\mathrm{CA}$ had significantly lower levels of
BDNF compared to Met carriers that did not report CA $\left(F_{1}, 506=4.19, P=.041, d=0.19\right)$, whereas individuals reporting CA who were homozygous for the Val allele had similar levels of BDNF compared to homozygous Val carriers without $\mathrm{CA}(P=.12)$. Furthermore, in individuals reporting no CA, Met carriers had higher levels of BDNF compared to homozygous Val carriers $\left(F_{1,629}=3.88, P=.049, d=0.19\right)$, while in the CA group, Met carriers had similar levels of BDNF compared to homozygous Val carriers $(P=.22)$. Exposure to recent stressful life events did not affect BDNF levels $(P=.79)$. No other interaction effects were found (all $P_{\mathrm{S}}>$.10).

\section{Dose-response associations between $C A$ and $B D N F$}

To investigate a dose-response association between CA and BDNF levels in the Met carriers versus the Val/Val group, 


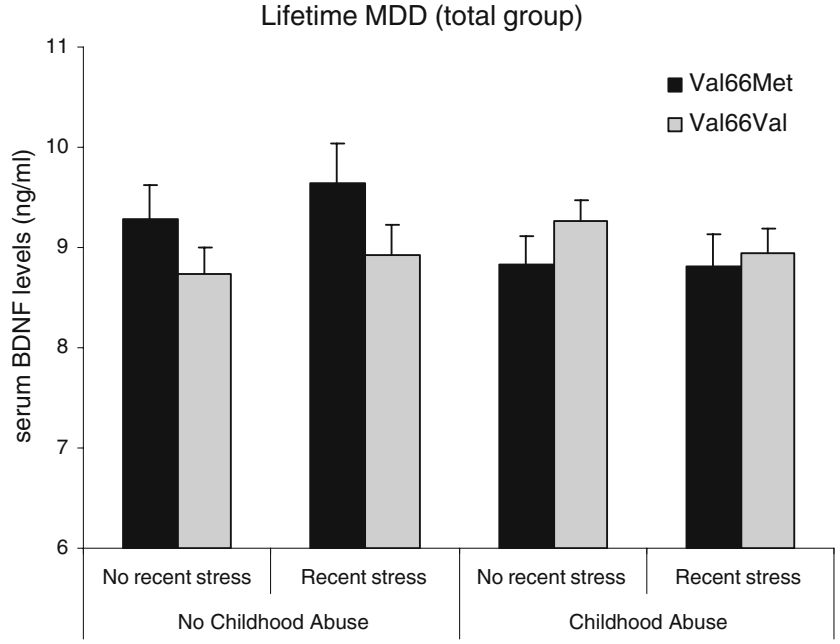

Fig. 1 Mean values of serum levels of BDNF by exposure to Childhood Abuse (CA), recent stressful events, and BDNF Val ${ }^{66} \mathrm{Met}$ in the total group of life-time MDD-patients $(n=1,435)$

additional 3 (categories of CA: no CA $(n=613)$ vs. one type of CA $(n=310)$ vs. two or more types of CA $(n=512)) \times 2$ (BDNF Val ${ }^{66}$ Met: homozygous Val/Val vs. Met carriers) ANOVA was conducted. An interaction was found between $\mathrm{CA}$ categories and $\mathrm{Val}^{66} \mathrm{Met}\left(F_{2,1,418}=2.99, P=.05\right)$. Post hoc comparisons showed that BDNF levels were only low in Met carriers when participants reported two or more types of CA compared to no CA $(P=.032)$, but not when they reported one type of CA $(P=.51)$, while in the homozygous Val carriers, no main effect of CA categories was found $(P=.29$, data not shown).

MDD without comorbid anxiety versus MDD with comorbid anxiety

\section{$M D D$ without comorbid anxiety}

We repeated the $2(\mathrm{CA}$ : yes $/$ no $) \times 2$ (recent stress: yes $/$ no $) \times 2$ (BDNF Val ${ }^{66} \mathrm{Met}$ : Val/Val vs. Met carriers) ANOVA on serum BDNF levels in individuals with an (lifetime) MDD without a comorbid anxiety disorder (MDD-, $n=402$, see Fig. 2). In the MDD- group, recent stress did affect BDNF levels $\left(F_{1,383}=7.19, P=.008, d=0.29\right)$, indicating lower BDNF levels in individuals reporting one or more recent stressful life events (mean $\pm \mathrm{SD}=8.24 \pm 3.20)$ compared to those who did not report negative life events (mean $\pm \mathrm{SD}=$ 9.16 \pm 3.06 ). Moreover, the interaction between $\mathrm{CA}$ and BDNF $\mathrm{Val}^{66}$ Met was also present in the MDD- group $\left(F_{1,383}=9.77, P=.002\right)$, with Met carriers who report CA having significantly lower serum levels of BDNF compared to Met carriers who did not report CA $\left(F_{1},{ }_{138}=10.03\right.$, $P=.002, d=0.44)$, whereas individuals reporting CA who were homozygous for the Val allele even had somewhat higher levels of BDNF compared to homozygous Val carriers without $\mathrm{CA}\left(F_{1}, 258=3.82, P=.052, d=0.23\right)$. Moreover, Met carriers with a reported history of CA showed low BDNF levels compared to homozygous Val carriers with reported CA $\left(F_{1,173}=7.45, P=.007, d=0.45\right)$, while Met carriers reporting no $\mathrm{CA}$ had higher BDNF levels compared to the nonabused homozygous Val carriers $\left(F_{1,223}=5.34, P=.022, d=0.23\right)$. There were no other main or interaction effects in the MDD- group.

Dose-response associations between recent stress and $B D N F$ in the $M D D^{-}$group

To evaluate whether there was a dose-response association between the number of reported recent life events and BDNF levels, an additional ANOVA was conducted on the three categories of recent stress: no $(n=232)$ vs one recent life event ( $n=92)$ vs two or more life events $(n=78)$, which confirmed the effect of recent stress $\left(F_{2}, 388=3.17, P=.04\right)$. However, post hoc comparisons showed that BDNF was not affected in a dose-dependent way: whereas individuals reporting one life event had lower BDNF levels (mean $\pm \mathrm{SD}, 8.19 \pm 3.09$ ) than those reporting no life event (mean $\pm \mathrm{SD}, 9.11 \pm 3.06 ; P=.018$; $d=0.30$ ), the group reporting two or more life events (mean $\pm \mathrm{SD}, 8.53 \pm 3.35$ ) did not differ from the group reporting no or one life event (both $P_{\mathrm{s}}>.10$ ).

\section{Dose-response associations between CA categories} and $B D N F$ in the $M D D^{-}$group

To investigate a dose-response association between $\mathrm{CA}$ and BDNF levels in Met carriers versus the homozygous Val

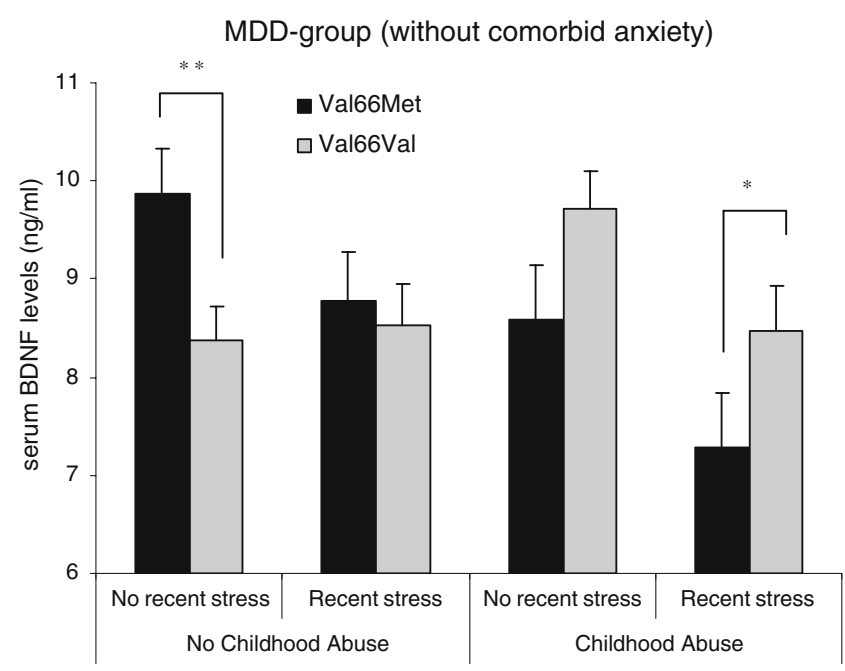

Fig. 2 Mean values of serum levels of BDNF by exposure to Childhood Abuse (CA), recent stressful events, and BDNF Val ${ }^{66} \mathrm{Met}$ in the group of lifetime MDD-patients without comorbid anxiety disorders $(n=402)$ 
group, an additional 3 (categories of CA: no CA $(n=225)$ vs one type of CA $(n=81)$ vs two or more types of CA $(n=96)) \times 2\left(\right.$ BDNF Val $^{66}$ Met: homozygous Val/Val vs. Met carriers) ANOVA was conducted (see Fig. 3). An interaction was found between $\mathrm{CA}$ categories and $\mathrm{Val}^{66} \mathrm{Met}\left(F_{3,383}=\right.$ 6.47, $P<.0001)$, indicating that BDNF levels decrease in Met carriers with increasing types of $\mathrm{CA}\left(F_{3},{ }_{132}=5.00\right.$, $P=.003)$, while in the homozygous Val carriers, no main effect of CA categories was found $(P=.11)$. Post hoc comparisons showed that BDNF levels were only low in Met carriers when participants reported two or more types of CA compared to no CA $(P=.001, d=0.63)$, but not when they reported one type of $\mathrm{CA}(P=.11)$. Moreover, Met carriers only had lower BDNF levels when reporting two or more types of CA compared to the $\mathrm{Val} / \mathrm{Val}$ group that reported two or more types of CA $(P=.006, d=0.66)$, but not when reporting one type of $\mathrm{CA}(P=.46)$. Furthermore, a main effect of $\mathrm{Val}^{66}$ Met also emerged $\left(F_{3}, 383=5.56, P=.019\right)$, with Met carriers having lower BDNF levels compared to $\mathrm{Val} / \mathrm{Val}$ individuals, regardless of CA categories.

\section{MDD with comorbid anxiety}

The results of the same ANOVA in the MDD+ANX group showed a main effect of recent stress on BDNF levels $\left(F_{1}, 1,014=4.14, P=.042, d=0.16\right)$. In contrast to the findings in the MDD- group, recent stress exposure was associated with elevated BDNF levels (mean $\pm \mathrm{SD}, 9.26 \pm 3.8$ ) compared to not being exposed to recent stressful events (mean $\pm \mathrm{SD}, 8.47 \pm 3.4$ ). Moreover, recent stress tended to interact with BDNF Val ${ }^{66} \mathrm{Met}\left(F_{1,1,014}=3.04, P=.082\right)$. No other main or interaction effects were significant in the MDD+ANX group.

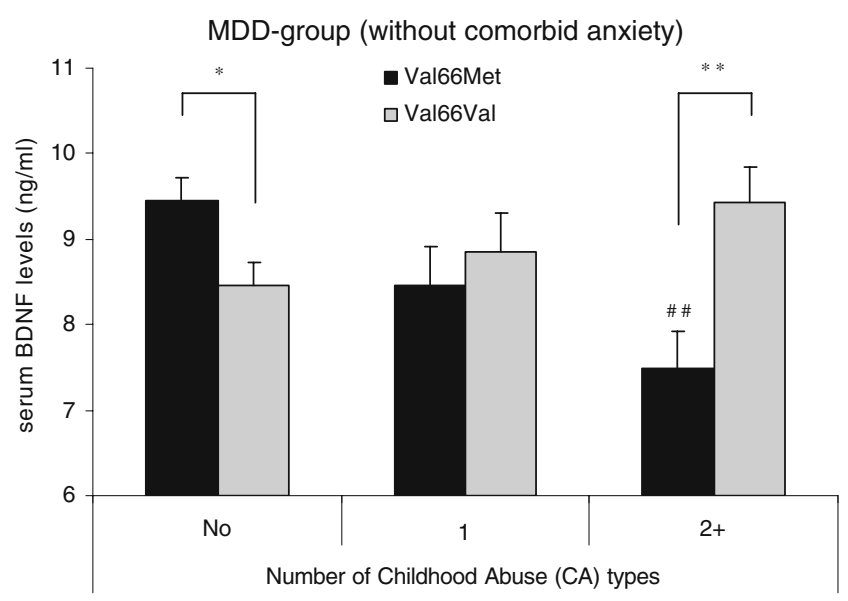

Fig. 3 Mean values of serum levels of BDNF by exposure to the number of Childhood Abuse (CA) types and BDNF Val ${ }^{66} \mathrm{Met}$ in lifetime MDDpatients without comorbid anxiety disorders $(n=402)$
Dose-response associations between recent stress categories and BDNF in the MDD+ANX group

To evaluate whether there was a dose-response association between the number of reported life events in the Val/Met vs. the $\mathrm{Val} / \mathrm{Val}$, an additional 3 (categories of recent stress: no $(n=606)$ vs one recent life event $(n=246)$ vs two or more life events $(n=181)) \times 2\left(\mathrm{BDNF} \mathrm{Val}^{66} \mathrm{Met}\right.$ : Val/Val vs. Met carriers) ANOVA was conducted. Here, only a trend for life events categories was found $\left(F_{2}, 1,016=2.33\right.$, $P=.098)$ and no interaction with $\mathrm{BDNF} \mathrm{Val}^{66} \mathrm{Met}$ $(P=.29)$. When comparing the means for the three recent stress groups post hoc, only individuals reporting one life event (mean $\pm \mathrm{SD}, 9.58 \pm 4.00$ ) had higher BDNF levels than those reporting no life events (mean $\pm \mathrm{SD}, 8.98 \pm 3.42 ; P=.031$ ), whereas the group reporting two or more life events (mean \pm $\mathrm{SD}, 9.14 \pm 3.42$ ) did not differ from the group reporting 1 or no life event (both $P_{\mathrm{S}}>.10$ ).

\section{Discussion}

The main new result of this study is that the impact of CA on serum BDNF levels appears to be dependent on variations on the $\mathrm{BDNF} \mathrm{Val}^{66} \mathrm{Met}$ polymorphism, at least in individuals with (lifetime) MDD without comorbid anxiety. In BDNF Met carriers, exposure to CA was associated with reduced serum levels of BDNF, and these differences were most pronounced in Met carriers who also reported negative life event(s) in the past year (see Fig. 2). In addition, these BDNF reductions associated with $\mathrm{CA}$ were linear in nature, so that BDNF levels were lowest in Met carriers reporting two or more types of CA. Moreover, these associations were not accounted for by the presence of a current diagnosis of MDD or by other potentially confounding factors, such as gender, or the use of an antidepressant, as these factors were added as covariates in the analyses and did not differ between the homozygous $\mathrm{Val} / \mathrm{Val}$ and the Met carriers. The Val/Val group, on the other hand, did not show reductions in BDNF levels related to $\mathrm{CA}$, and in the MDD group without comorbid anxiety, BDNF levels were even higher in Val/Val participants reporting $\mathrm{CA}$. Taken together, these findings are in line with the idea that Met carriers are more sensitive to stressinduced downregulation of BDNF.

A second main finding is that exposure to stressful events that occurred in the past year reduced BDNF levels, independent of variations on the BDNF $\mathrm{Val}^{66} \mathrm{Met}$ polymorphism, at least in the MDD group without comorbid anxiety. These results extend the finding of two previous studies showing lowered BDNF levels in bipolar patients reporting negative life events (Kauer-Sant'Anna et al. 2007), and in women with high risk of depression reporting recent life 
events (Trajkovksa et al. 2008). In the group with comorbid anxiety, recent stress exposure was associated with increased BDNF levels, however. Moreover, while CA was associated with reduced BDNF in the Met carriers, BDNF levels were not affected by $\mathrm{CA}$ in the comorbid group. These findings seem to suggest that comorbid anxiety disorder may counteract the downregulation of BDNF associated with CA and recent stressful event. So far, it is unclear how this relates to the symptomatology of MDD with and without comorbid anxiety, particularly because CA has specifically been linked to comorbidity of MDD and anxiety disorders (Hovens et al. 2009). Moreover, some studies have associated the $\mathrm{Val} / \mathrm{Val}$ polymorphism with patterns of anxiety, rather than with depressive symptoms (Gatt et al. 2009), but in the group with comorbid anxiety disorders, we did not find any indications that $\mathrm{Val} / \mathrm{Val}$ individuals have lower BDNF levels.

Although it should be taken into account that this is a cross-sectional study, preventing causal inferences about the impact of CA, it is remarkable that exposure to CA, which occurred in many individuals more than 25 years ago, is associated with decreased BDNF levels, at least in Met carriers without comorbid anxiety disorders. These reductions of serum BDNF levels in individuals with reported CA suggest that exposure to chronic stress during childhood may lead to a long-lasting downregulation of the neurotrophic system, which might be further reduced by recent stressful events. These results extend the findings of previous studies showing lower levels of peripheral BDNF in patients with current MDD and a history of CA (GrassiOliveira et al. 2008). Since variations at the $\mathrm{Val}^{66} \mathrm{Met}$ locus were not taken into account in this study, it remains unclear whether the effects of CA were mainly driven by Met carriers, as might be expected on the basis of our results.

The finding of reduced BDNF levels in Met carriers is also of interest when considered in the context of previous findings, indicating that Met carriers are particularly vulnerable to the impact of CA with respect to depressive symptoms (Gatt et al. 2009; Kaufman et al. 2006; Wichers et al. 2008) and enhanced loss of hippocampal-lateral prefrontal gray matter (Gatt et al. 2009), given that low BDNF levels are associated with MDD (Sen et al. 2008). Moreover, reductions in BDNF expression can have a direct impact on neuronal growth and plasticity in frontohippocampal networks (Murakami et al. 2005; Roceri et al. 2004; Song et al. 2006; Smith et al. 1995). It should be noted that, in our sample, no associations were found between Met carriers and higher depression severity after CA, however, which is consistent with some recent studies (see Aguilera et al. 2009; Nederhof et al. 2010). Definitely, longitudinal studies are needed to further unravel the developmental trajectories relating exposure to $\mathrm{CA}$ and recent life events to low BDNF levels and altered brain structures and functioning.
One other interesting observation is that variations on the BDNF Val ${ }^{66}$ Met polymorphism itself were not directly associated with variations in BDNF levels even though, among individuals reporting no CA, Met carriers had higher BDNF levels compared to homozygous Val carriers. Very few studies in humans investigated the association between the BDNF $\mathrm{Val}^{66}{ }^{6}$ Met polymorphism and serum BDNF levels. One study in psychological healthy individuals also reported enhanced serum BDNF levels in Met carriers compared to $\mathrm{Val} / \mathrm{Val}$ individuals (Lang et al. 2009). Two other studies did not find an association between the $\mathrm{Val}^{66} \mathrm{Met}$ polymorphism and variations in peripheral BDNF levels, not in a sample of depressed patients (Duncan et al. 2009) nor among healthy twins with and without a co-twin history of affective disorder (Vinberg et al. 2009), even though in this last study, BDNF levels were higher among a subgroup of Met carriers at high risk for depression or bipolar disorder. Taken together, findings regarding associations between the $\mathrm{Val}^{66} \mathrm{Met}$ polymorphism and variations in peripheral BDNF levels in humans are mixed. This could be due to the fact that, in previous studies, neither CA nor exposure to recent stressful events has been taken into account. Furthermore, this might also be related to the fact that the direct associations between $\mathrm{Val}^{66} \mathrm{Met}$ and BDNF levels, if anything, appear to be rather small in individuals reporting no CA (in our study $d=0.19$ ) and thus can only be detected in large samples.

In sum, this study has shown that CA is associated with reduced BDNF levels in Met carriers with lifetime MDD (without comorbid anxiety), whereas serum BDNF levels of $\mathrm{Val} /$ Val carriers do not seem to be affected by CA. A number of limitations should be taken into account when evaluating these findings. First, the reliability of participants' recall of events from childhood may vary, given the long time gap between occurrence and recall. Self-reported CA requires caution when interpreting the results, although Goodman et al. (1999) observed good reliability among psychiatrically ill women. Related to this, one cannot rule out that the association between $\mathrm{CA}$ or recent stress and low BDNF levels in individuals with lifetime MDD could (in part) be spurious, in the sense that individuals with a current depressed mood might have low BDNF levels and also experience life events in a (more) negative way, without these factors being directly related to each other. We do not consider this possibility very likely, however. First of all, we have previously shown that, in the NESDA sample, the association between negative life events and depression is independent of current mood state (Spinhoven et al. 2010). Moreover, in all statistical analyses, we added current vs remitted MDD as a covariate, and the associations between life events and BDNF remain statistically significant when taking current mood state into account. A longitudinal design would 
be optimal to assess whether predifferences-postdifferences in serum BDNF are directly affected by stressful events. Another limitation is that we assessed serum BDNF levels, which may not be a direct measure of central BDNF, even though previous studies in animals showed that BDNF can cross the bloodbrain barrier in both directions (Pan et al. 1998) and a strong association has been reported between central and peripheral BDNF levels (Karege et al. 2002). A third limitation is that we only assessed the $\mathrm{Val}^{66} \mathrm{Met}$ variant, whereas there are more loci on the BDNF gene that might be associated with variations in serum BDNF levels. Moreover, gene $\times$ gene interactions, particularly with the 5HTT-LPR polymorphism, were not addressed in this study, whereas these interactions have been shown to be relevant in predicting depression severity in combination with CA in some studies (see Kaufman et al. 2006; Wichers et al. 2008), although not in others (Gatt et al. 2009).

Despite the considerations mentioned above, the findings of this study highlight the importance of investigations that focus on integrating candidate genes, BDNF levels, and environmental stressors and provide new and important evidence to suggest that a chain of events, commencing with $\mathrm{G} \times \mathrm{E}$ interactions and their impact on (set points of) BDNF, may lead to low BDNF levels in patients with lifetime MDD.

Open Access This article is distributed under the terms of the Creative Commons Attribution Noncommercial License which permits any noncommercial use, distribution, and reproduction in any medium, provided the original author(s) and source are credited.

\section{References}

Aguilera M, Arias B, Wichers M, Barrantes-Vidal N, Moja J, Villa H, van Os J, Ibáñez MI, Ruipérez MA, Ortet G, Fañanás L (2009) Early adversity and 5-HTT/BDNF genes: new evidence of geneenvironment interactions on depressive symptoms in a general population. Psychol Med 39:1425-1432

American Psychiatric Association (1994) Diagnostic and statistical manual of mental disorders, 4th edn. American Psychiatric Association, Washington

Angelucci F, Brene S, Mathe AA (2005) BDNF in schizophrenia, depression and corresponding animal models. Mol Psychiatry $10: 345-352$

Begliuomini S, Lenzi E, Ninni F, Casarosa E, Merlini S, Pluchino N et al (2008) Plasma brain-derived neurotrophic factor daily variations in men: correlation with cortisol circadian rhythm. J Endocrinol 197:429-435

Boomsma DI, Willemsen G, Sullivan PF, Heutink P, Meijer P, Sondervan D, Kluft C, Smit G, Nolen WA, Zitman FG, Smit JH, Hoogendijk WJ, van Dyck R, de Geus EJC, Penninx BWJH (2008) Genomewide association of major depression: description of samples for the GAIN major depressive disorder study: NTR and NESDA biobank projects. Eur J Hum Genet 16:335-342

Brugha TS, Cragg D (1990) The list of threatening experiences: the reliability and validity of a brief life events questionnaire. Acta Psychiatr Scan 82:77-81
Brugha T, Bebbington P, Tennant C, Hurry J (1985) The list of threatening experiences: a subset of 12 life event categories with considerable long-term contextual threat. Psychol Med 15:189-194

Bueller JA, Aftab M, Sen S, Gomez-Hassan D, Burmeister M, Zubieta $\mathrm{JK}$ (2006) BDNF $\mathrm{Val}^{66}$ Met allele is associated with reduced hippocampal volume in healthy subjects. Biol Psychiatry $59: 812-815$

Charney DS (2004) Psychobiological mechanisms of resilience and vulnerability. Focus 2:368-391

Cohen J (1988) Statistical power analysis for the behavioral sciences. Erlbaum, Hillsdale

de Graaf R, Bijl RV, ten Have M, Beekman ATF, Vollebergh WAM (2004a) Pathways to comorbidity: the transition of pure mood, anxiety and substance abuse disorders into comorbid conditions in a longitudinal population based study. J Affect Disord 82:461467

de Graaf R, Bijl RV, ten Have M, Beekman ATF, Vollebergh WAM (2004b) Rapid onset of comorbidity of common mental disorders: findings from the Netherlands Mental Health Survey and Incidence Study (NEMESIS). Acta Psychiatr Scand 109:55-63

Duman RS, Monteggia LM (2006) A neurotrophic model for stressrelated mood disorders. Biol Psychiatry 59:1116-1127

Duncan LE, Hutchison KE, Carey G, Craighead WE (2009) Variation in brain-derived neurotrophic factor (BDNF) gene is associated with symptoms of depression. J Affect Disord 115:215-219

Egan MF, Kojima M, Callicott JH, Goldberg TE, Kolachana BS, Bertolino A, Zaitsev E, Gold B, Goldman D, Dean M, Lu B, Weinberger DL (2003) The BDNF $\mathrm{val}^{66}$ met polymorphism affects activity-dependent secretion of BDNF and human memory and hippocampal function. Cell 112:257-269

Gatt JM, Nemeroff CB, Dobson-Stone C, Paul RH, Bryant RH, Schofield $\mathrm{R}$ et al (2009) Interactions between BDNF val ${ }^{66}$ met polymorphism predict brain and arousal pathways to syndromal depression and anxiety. Mol Psychiatry 14:681-695

Grassi-Oliveira R, Stein LM, Lopes RP, Teixeira AL, Bauer ME (2008) Low plasma brain-derived neurotrophic factor and childhood physical neglect are associated with verbal memory impairment in major depression-a preliminary report. Biol Psychiatry 64:281-285

Goodman LA, Thompson KM, Weinfurt K, Corl S, Acker P, Mueser KY, Rosenberg SD (1999) Reliability of reports of violent victimization and posttraumatic stress disorder among men and women with serious mental illness. J Trauma Stress 12:587-599

Heim C, Nemeroff CB (2001) The role of childhood trauma in the neurobiology of mood and anxiety disorders: preclinical and clinical studies. Biol Psychiatry 49:1023-1039

Hovens JGFM, Wiersma JE, Giltay EJ, van Oppen P, Spinhoven P, Penninx BWJH, Zitman FG (2009) Childhood life events and childhood trauma in adult patients with depressive, anxiety and comorbid disorders vs. controls. Acta Psychiatr Scand 122:66-74

Karege F, Schwald M, Cisse M (2002) Postnatal developmental profile of brain-derived neurotrophic factor in rat brain and platelets. Neurosci Lett 328:261-264

Karege F, Bondolfi G, Gervasoni N, Schwald M, Aubry J-M, Bertschy G (2005) Low brain-derived neurotrophic factor (BDNF) levels in serum of depressed patients probably result from lowered platelet BDNF release unrelated to platelet reactivity. Biol Psychiatry 57:1068-1072

Kauer-Sant'Anna M, Tramontina J, Andreazza AC, Cereser K, daCosta S, Santin A, Yatham LN, Kapczinski F (2007) Traumatic life events in bipolar disorder: impact on BDNF levels and psychopathology. Bipolar Disord 9:S128-S135

Kaufman J, Yang B-Z, Douglas-Palumberi H, Grasso D, Lipschitz D, Houshvar S, Krystal JH, Gelertner J (2006) Brain-derived neurotrophic factor-5-HTTLPR gene interactions and environmental modifiers of depression in children. Biol Psychiatry 59:673-680 
Kendler KS (2005) "A gene for ...": the nature of gene action in psychiatric disorders. Am J Psychiatry 162:1243-1252

Kendler KS, Karowski L, Prescott CA (1999) Causal relationships between stressful life events and the onset of major depression. Am J Psychiatry 156:837-841

Lang UE, Hellweg R, Sander T, Gallinat J (2009) The Met allele of the BDNF Val ${ }^{66}$ Met polymorphism is associated with increased serum BDNF concentrations. Mol Psychiatry 14:120-122

McLaughlin KA, Greif Green J, Gruber MJ, Sampson MA, Zaslavsky AM, Kessler RC (2010) Childhood adversities and adult psychiatric disorders in the national comorbidity survey replication II. Arch Gen Psychiatry 67:124-132

Molendijk ML, Bus BAA, Spinhoven Ph, Penninx, BJWH, Kenis G, Prickaerts J, Oude Voshaar RC, Elzinga BM (2010) Serum levels of brain-derived neurotrophic factor in major depressive disorder: state and trait issues, clinical features, and pharmacological treatment. Mol Psychiatry (in press)

Murakami S, Imbe H, Morikawa Y, Kubo C, Senba E (2005) Chronic stress, as well as acute stress, reduces BDNF mRNA expression in the rat hippocampus but less robustly. Neurosci Res 53:129-139

Nederhof E, Bouma, EM, Oldewinkel AJ, Ormel J (2010) Interaction between childhood adversity, brain-derived neurotrophic factor $\mathrm{val} / \mathrm{met}$ and serotonin transporter promoter polymorphism on depression: the TRAILS study. Biol Psychiatry 68:209-212

Pan W, Banks WA, Fasold MB, Bluth J, Kastin AJ (1998) Transport of brain-derived neurotrophic factor across the blood-brain barrier. Neuropharmacology 37:1553-1561

Penninx BJWH, Beekman ATF, Smit JH, Zitman FG, Nolen WA, Spinhoven P, Cuijpers P, De Jong PJ, Van Marwijk WJ, Assendelft WJJ, Van der Meer K, Verhaak P, Wensing M, De Graaf R, Hoogendijk WJ, Ormel J, Van Dyck R, for the NESDA Research Consortium (2008) The Netherlands Study of Depression and Anxiety (NESDA): rationale, objectives and methods. Int J Methods Psychiatr Res 17:121-140

Pezawas L, Verchinski BA, Mattay VS, Callicot JH, Kolachana BS, Straub RE, Egan MF, Myer-Lindenberg A, Weinberger DR (2004) The brainderived neurotrophic factor $\mathrm{Val}^{66} \mathrm{Met}$ polymorphism and variation in human cortical morphology. J Neurosci 24:10088-101010

Post RM (2007) Kindling and sensitization as models for affective episode recurrence, cyclicity, and tolerance phenomena. Neurosci Biobehav Rev 31:858-873

Roceri M, Cirulli F, Pessina C, Peretto P, Racagni G, Riva MA (2004) Postnatal repeated maternal deprivation produces age-dependent changes of brain-derived neurotrophic factor expression in selected rat brain regions. Biol Psychiatry 55:708-714
Rush AJ, Gullion CM, Basco MR, Jarrett RB, Trivedi MH (1996) The Inventory of Depressive Symptomatology (IDS): psychometric properties. Psychol Med 26:477-486

Sen S, Duman R, Sanacora G (2008) Serum brain-derived neurotrophic factor, depression, and antidepressant medications: meta-analyses and implications. Biol Psychiatry 64:527-532

Smith MA, Makino S, Kvetnansky R, Post RM (1995) Stress and glucocorticoids affect the expression of brain-derived neurotrophic factor and neurotrophin-3 mRNAs in the hippocampus. $\mathrm{J}$ Neurosci 15:1768-1777

Song L, Che W, Min-Wei W, Murakami Y, Matsumoto K (2006) Impairment of the spatial learning and memory induced by learned helplessness and chronic mild stress. Pharmacol Biochem Behav 83:186-193

Spinhoven Ph, Elzinga BM, Hovens JGFM, Roelofs K, Zitman FG, van Oppen P, Penninx BWJH (2010) The specificity of childhood adversities and negative life events across the life span to anxiety and depressive disorders. J Affect Disord. doi:10.1016/j.jad.2010.02.132

Trajkovska V, Marcussen AB, Vinberg M, Hartvig P, Aznar S, Knudsen GM (2007) Measurements of brain-derived neurotrophic factor: methodological aspects and demographical data. Brain Res Bull 73:143-149

Trajkovksa V, Vinberg M, Aznar S, Knudsen GM, Kessing LA (2008) Whole blood BDNF levels in healthy twins discordant for affective disorder: association to life events and neuroticism. J Affect Disord 108:165-169

Vinberg M, Trajkovska V, Bennike B, Knorr U, Knudsen GM, Kessing LV (2009) The BDNF Val ${ }^{66}$ Met polymorphism: relation to familiar risk of affective disorder, BDNF levels and salivary cortisol. Psychoneuroendocrinology 34:1380-1389

Wacker HR, Battegay R, Mullejans R, Schlosser C (2006) Using the CIDI-C in the general population. In: Stefanis CN, Rabavilas AD, Soldatos CR (eds) Psychiatry: a world perspective. Elsevier, Amsterdam, pp 138-143

Wichers M, Kenis G, Jacobs N, Mengelers R, Derom C, Vlietinck R, van Os J (2008) The BDNF Val ${ }^{66}$ Met $\times 5$-HTTLPR $\times$ child adversity interaction and depressive symptoms: an attempt at replication. Am J Med Genet Part B: Neuropsychiatr Genet 147B:120-123

Wittchen HU, Robins LN, Cottler LB, Sartorius N, Burke JD, Regier D (1991) Cross-cultural feasibility, reliability and sources of variance of the Composite International Diagnostic Interview (CIDI). The multicentre WHO/ADAMHA field trials. $\mathrm{Br} \mathrm{J}$ Psychiatry 159:645-653 